\title{
Accident and emergency department attendance by asthmatic children
}

\author{
S M O'HALLORAN, D P HEAF \\ From the Respiratory Unit, Royal Liverpool Children's Hospital (Alder Hey), Liverpool
}

ABSTRACT Attendances at the accident and emergency department of a children's hospital for treatment of acute asthma were studied for one year to determine the characteristics of the children attending and their management. Eight hundred and twenty children, median age 5.5 years, made 1389 visits. Records were available from 1046 visits. Clinical information and assessment of the severity of the attack in the department was often inadequate. Peak flow records were available for $366(35 \%)$. Attendances were most frequent in September and during the evening, but there was no significant day to day variation. Eight hundred and three children (78\%) were self referred. Before attendance $962(92 \%)$ had used a bronchodilator, including nebulised salbutamol (11\%); $2 \%$ had taken prednisolone and $21 \%$ antibiotics. Five hundred and sixteen visits $(49 \%)$ led to admission and $19 \%$ of those admitted required intravenous treatment. Probably some children who at present attend hospital for treatment of acute asthma could be managed at home, but this cannot be assumed without better understanding of the reasons for hospital attendance. More information is needed.

\section{Introduction}

Asthma is the most common chronic illness of childhood, affecting about $10 \%$ of school age children. ${ }^{12}$ Optimal management requires both prompt treatment of acute attacks and regular review of prophylaxis. In most cases this is best carried out by the general practitioner, who is readily accessible and who knows the child and his family. ${ }^{34}$ Hospital admissions for asthma are, however, increasing steadily, ${ }^{5-7}$ and there is evidence that many parents bypass their general practitioner and take their children directly to hospital. ${ }^{6}$ Hospitals are always available, but are not necessarily the best place for children to be treated. In accident and emergency departments children are likely to be seen by junior doctors who are inexperienced in the management of asthma. Reed et al have shown many shortcomings in the treatment of asthma in the accident and emergency department in a general teaching hospital. ${ }^{8}$ Facilities for long term follow up are unlikely to be available and the general practitioner's care may be undermined if he is unable to see his patients during an acute attack. To provide a comprehensive service for asthmatic children, we need

Address for reprint requests: Dr O'Halloran, Respiratory Unit, Royal Liverpool Children's Hospital (Alder Hey), Liverpool L12 2AP.

Accepted 28 June 1989 to know how many need emergency treatment for acute attacks, and the proportions who need hospital care and who could be adequately managed at home. To examine emergency attendance for acute asthma at a children's hospital we have carried out a one year survey in the accident and emergency department, reviewing the numbers of children attending, management in the department, and admission rates.

\section{Methods}

The Royal Liverpool Children's Hospital (Alder Hey) is the largest children's hospital in the United Kingdom. The accident and emergency department serves a population of about 150000 children up to the age of 16. It is the main children's emergency unit for Liverpool and the surrounding area, though there is a small department in the city branch of the hospital and some children are seen in the accident and emergency departments of three general hospitals in the city. Casualty officers are general practice trainees or career paediatricians; most have no previous paediatric experience. Children referred to the admitting paediatric registrars (all of whom have paediatric experience of one to two years) are assessed in the department; direct presentation to the wards is unusual. Children attending Alder Hey come from all parts of Liverpool. The social class distribution of a 
group of 300 asthmatic children attending the department ${ }^{9}$ corresponds closely to the pattern for Liverpool as a whole. About $60 \%$ of asthmatic children attending the accident and emergency department in this study are under the care of one of eight consultants at the hospital, one of whom is a specialist in respiratory disease; the rest attend only for emergency treatment.

Children recorded in the receptionists' desk book as attending with asthma, "wheeze," "bronchitis," cough, "chestiness," chest pain, or difficulty in breathing from 1 January to 31 December 1986 were identified. Records from attendances were either filed in the department, transferred to the ward if the child was admitted, or sent to the outpatient booking office if a referral to a consultant was made. Records were retrieved daily and data collected from those considered by the examining doctor to have asthma. Children under the age of 18 months were excluded because of the difficulty of establishing a diagnosis of asthma in this age group.

The data sought were: name, address, date of birth, sex, date and time of visit, person referring (parents, own doctor, or deputising service), contents of referral letter, duration of symptoms before attendance, apparent precipitating factors, treatment at home, physical signs on arrival (including peak expiratory flow rate, measured with a mini Wright peak flow meter), treatment in the department, whether admitted or discharged, whether the child returned to the hospital during the same attack, and treatment given in the ward if admitted.

Comparison of admission and discharge data was carried out with the $\chi^{2}$ test, with Yates' correction where applicable, for categorical variables, and the $t$ test with separate variance analysis for continuous variables, the Statistics Program for the Social Sciences being used.

\section{Results}

During 1986 there were 40853 new medical and surgical attendances at the accident and emergency department. Records were available for 1046 visits for acute asthma; 343 further attendances for asthma were identified from the desk book but records could not be traced. Visits by children recorded as having symptoms such as "wheezy" were not included if records were not available unless they were known to have asthma. Examination of records showed that most children described as "chesty" or with cough had conditions other than asthma, usually a respiratory infection. Information recorded in the department was frequently inadequate, especially for details of treatment and the child's condition on arrival. There was

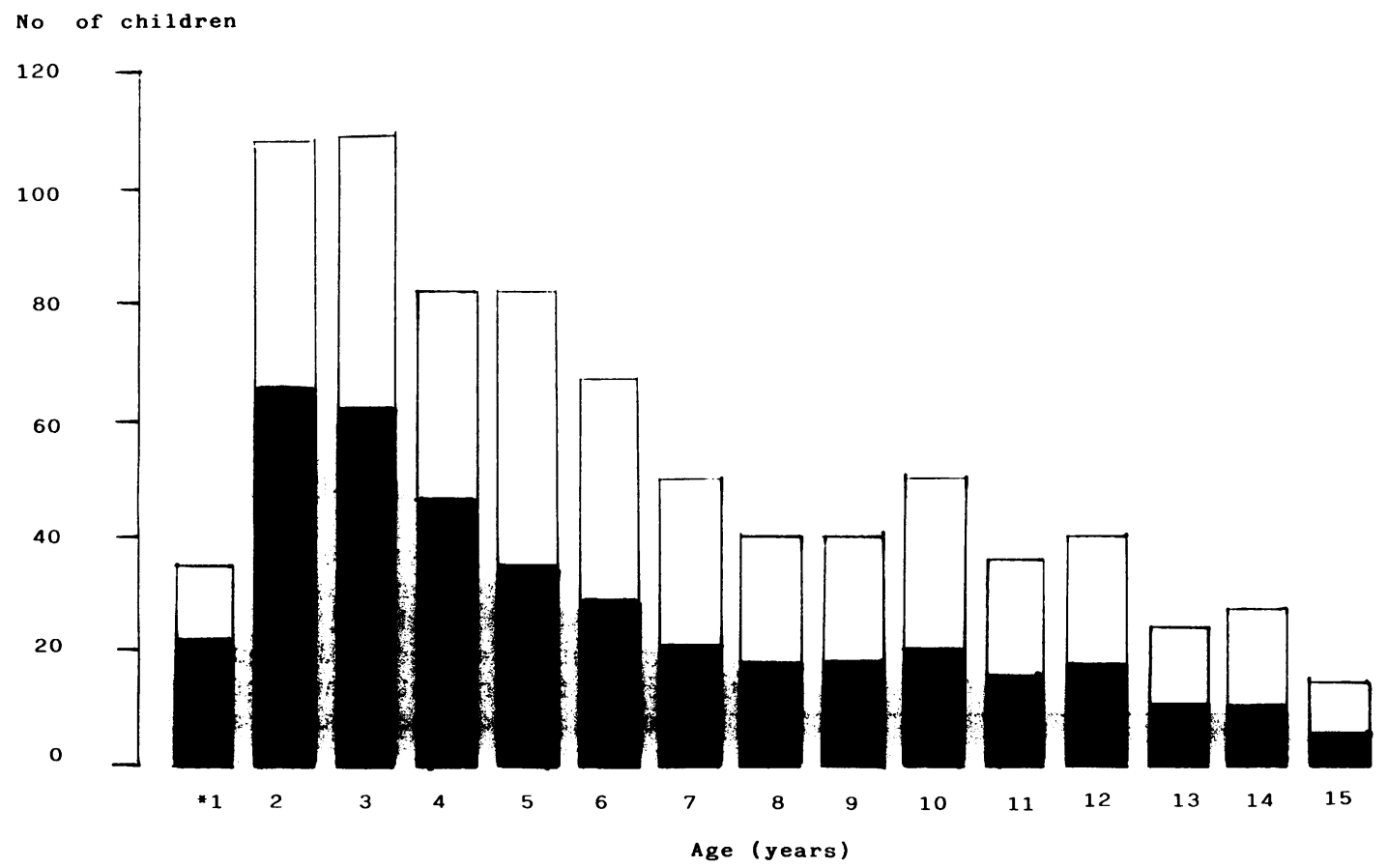

Fig 1 Age distribution of 820 children attending the accident and emergency department with acute asthma, January-December 1986. Children admitted; * children under 1.5 years excluded. 


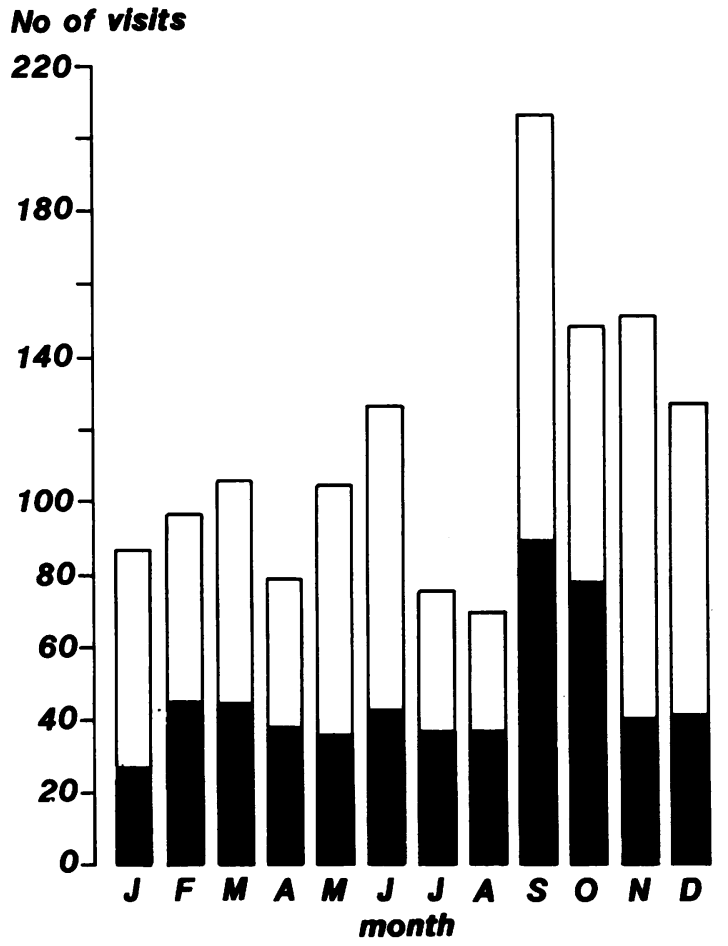

Fig 2 Number of visits to the accident and emergency department by 820 children with acute asthma,

January-December 1986. Children admitted.

no variation in the number of data recorded with time of day. All results other than the total number of visits per month are based on 1046 records.

The total number of 1389 visits for asthma accounted for $3.4 \%$ of all visits to the department and $8.5 \%$ of those not due to trauma. They were made by 820 children aged from 18 months to 16 years, of whom $540(67 \%)$ were boys. The median age of the children was 5.5 years, reflecting a substantial excess of young children (fig 1).

TIME OF ATTENDANCE

Visits were more frequent in the winter months (fig 2)

Table 1 Day and time of attendance (1046 visits)

\begin{tabular}{lllc}
\hline Day & $\begin{array}{l}\% \text { of } \\
\text { visits }\end{array}$ & Time & $\begin{array}{c}\% \text { of } \\
\text { visits }\end{array}$ \\
\hline Sunday & 17 & & \\
Monday & 17 & $0001-0040$ & 10 \\
Tuesday & 16 & $0401-0800$ & 6 \\
Wednesday & 13 & $0801-1200$ & 17 \\
Thursday & 11 & $1201-1600$ & 18 \\
Friday & 13 & $1601-2000$ & 23 \\
Saturday & 12 & $2001-2400$ & 26 \\
Bank Holiday & 1 & & \\
\hline
\end{tabular}

Table 2 Drug treatment before attendance (1001 visits)

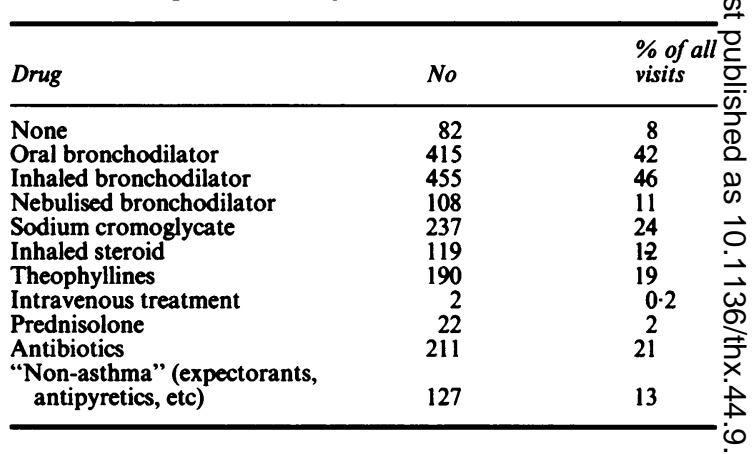

but the single busiest month was September (207 visits, $15 \%$ ) and the quietest August (70 visits, 5\%). Sunday 응 and Monday were the busiest days of the week, Thursday and Saturday the quietest (table 1). Analysis $c$ of the time of day of attendance showed that visits $\mathbb{D}$ were most frequent in the afternoon and evening $(67 \% \stackrel{\mathbb{D}}{\mathbb{D}}$ between midday and midnight) and unusual in the $\frac{\vec{\sigma}}{\mathrm{O}}$ early hours of the morning (table 1).

REFERRAL

Eight hundred and three visits $(78 \%)$ represented self. referrals by parents, $163(16 \%)$ referrals by the child's own doctor, and $70(6 \%)$ referrals by the deputising service. One hundred and forty referrals $(60 \%)$ were made to the casualty officer and $93(40 \%)$ to the $\frac{\circ}{8}$ admitting registrar. Letters were available for $99 \%$ of $\triangle$ children referred by a doctor; $153(67 \%)$ included a $\overrightarrow{\overrightarrow{0}}$ diagnosis of asthma and $165(72 \%)$ details of treatment before attendance at hospital.

CONDITION BEFORE ARRIVAL

Symptoms had been present for a short time in most cases, the median duration being one day. Apparent $\stackrel{x}{-}$ precipitating causes were recorded in 866 cases. The $\frac{0}{3}$ most common was symptoms of an upper respiratory tract infection- 645 cases $(75 \%)$. Exposure to an $\frac{0}{3}$ agent known to provoke attacks $(4 \%)$, excitement $(3 \%)$, and missing treatment $(2 \%)$ were uncommon. No cause was apparent in 142 cases $(16 \%)$.

\section{DRUG TREATMENT AT HOME}

Drug treatment at home was recorded for 1001 visits and is shown in table 2 . Records usually listed ${ }_{N}$ treatment only and did not distinguish between treat- $\omega$ ment for the current attack and regular drugs. Table $2 \%$ presents the combined data to avoid supposition $\stackrel{0}{\subset}$ about how treatment was used.

CONDITION ON ARRIVAL

Physical signs on arrival that were sought from the $\frac{\vec{P}}{\mathbb{D}}$ records were: heart rate, respiratory rate, peak $\frac{\rho}{\Phi}$ expiratory flow (PEF) in children over five years, 
Table 3 Physical signs on arrival

\begin{tabular}{|c|c|c|c|c|}
\hline \multirow{3}{*}{$\begin{array}{l}\text { Sign } \\
\text { Heart rate (beats/min) } \\
\text { Respiratory rate } \\
\text { (beats/min) } \\
\text { PEF }(1 / \mathrm{min})^{*}\end{array}$} & \multicolumn{2}{|c|}{$\begin{array}{l}\text { No }(\%) \\
\text { recorded }\end{array}$} & \multirow{2}{*}{$\frac{\text { Range }}{68-200}$} & \multirow{2}{*}{$\begin{array}{l}\text { Median } \\
120\end{array}$} \\
\hline & 852 & (81) & & \\
\hline & $\begin{array}{l}825 \\
194\end{array}$ & $\begin{array}{l}(79) \\
(35)\end{array}$ & $\begin{array}{r}16-80 \\
5-425\end{array}$ & $\begin{array}{l}36 \\
130 \\
\text { (mode 60) }\end{array}$ \\
\hline $\begin{array}{l}\text { Paradox } \\
\text { Recession } \\
\text { Cyanosis } \\
\text { Speech } \\
\text { Rhonchi }\end{array}$ & $\begin{array}{r}255 \\
758 \\
458 \\
229 \\
1001\end{array}$ & $\begin{array}{l}(24) \\
(72) \\
(44) \\
(22) \\
(96)\end{array}$ & \multicolumn{2}{|c|}{$\begin{array}{l}\text { Details }(N o(\%)) \\
\text { Present in } 38(15) \\
\text { Present in } 568(75) \\
\text { Present in } 22(5) \\
\text { Able to speak: } 162(71) \\
\text { "Present": } 962(96) \\
\text { "Absent": } 39(4)\end{array}$} \\
\hline
\end{tabular}

*Peak expiratory flow: only for children aged 5 years and older.

presence of pulsus paradoxus, cyanosis, recession of the chest wall, ability to speak, quality of air entry, and rhonchi. The number of cases in which each sign was recorded ranged from $81 \%$ for heart rate to $22 \%$ for ability to speak (table 3). PEF was available for $35 \%$ of patients. The values of heart rate, respiratory rate and recorded PEF showed a wide range (table 3).

\section{TREATMENT IN THE ACCIDENT AND EMERGENGY DEPARTMENT}

On 104 occasions no treatment was given, either because the child's symptoms had abated on arrival or because he was transferred to the ward immediately. In 926 visits $(89 \%)$ nebulised salbutamol was given alone. Administration of intravenous aminophylline and hydrocortisone was initiated in the department on 22 occasions $(2 \%)$. A short course of prednisolone for taking home was given in 46 instances $(4 \%)$.

\section{ADMISSION AND DISCHARGE}

On 446 occasions (43\%) the child was admitted at once and on $496(47 \%)$ he went home and did not return. A further 94 children were discharged $(16 \%$ of those discharged) but returned for further treatment during the attack and 70 of these were then admitted to the ward. The total number of admissions was therefore $516(49 \%)$. There were 4637 medical admissions to the hospital during 1986; asthma accounted for $11 \%$ of these.

\section{TREATMENT AFTER ADMISSION}

After admission all children received nebulised salbutamol. A short course of oral prednisolone was given to 208 (40\% of admissions, $20 \%$ of visits). Intravenous aminophylline and hydrocortisone (a standard regimen in the hospital for those needing intravenous treatment) were given on 98 occasions ( $9 \%$ of visits and in $19 \%$ of admissions). Young children and those aged 11 and over needed intravenous treatment more often ( $0-2$ years, 27 children,
Table 4 Physical signs and admission

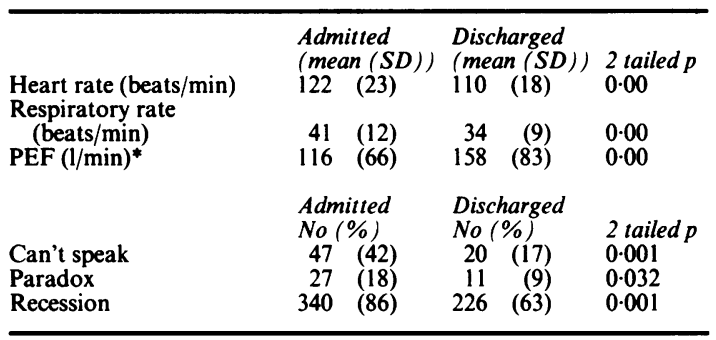

*Peak expiratory flow: only for children aged 5 years and over.

$23 \%$; 3-4 years, 27 children, $18 \%$; 5-10 years, 24 children, $13 \% ; \geqslant 11$ years, 20 children, $31 \%$ ). No one admitted through the accident and emergency department required intensive care and there were no deaths.

\section{ADMISSION}

Data were reviewed to assess which features of attendance were associated with admission. The percentages refer to the proportion of children in each category.

Young children were admitted more frequently than older ones (fig 1). There was no constant relation between total attendances and admissions each month (fig 2). The greatest proportion of admissions occurred in August $(37 / 70,53 \%)$ and the lowest in November $(40 / 152,26 \%)$.

Children referred by a doctor were admitted more often $(160 / 233,70 \%)$ than those who were self referred $(357 / 803,46 \% ; p=<0.001)$. Admission was more common when the attack had been present for a short time. The mean duration of symptoms was 1.8 days in admitted children and 2.7 days in those sent home ( $p$ $<0.05$ ). Preceding upper respiratory tract symptoms increased the likelihood of admission, being present in $53 \%$ of those admitted compared with $47 \%$ of those discharged $(p<0.05)$. Physical signs on arrival showed evidence of a more severe attack in admitted children (table 4).

Sex, time and day of visit, and possible precipitating factors had no effect on admission. Children who made repeated visits to the accident and emergency department during the study year had admission rates similar to those of children attending only once ( $53 \%$ and $52 \%$ respectively).

\section{Discussion}

This study was intended to provide information on attendance and practice in the management of acute asthma in the accident and emergency department of a children's hospital serving most of a large urban area. 
The study was retrospective and no attempt was made to alter practice in the department.

The study shows asthma to be a common reason for attendance, accounting for $3 \%$ of all visits, $8.5 \%$ of non-trauma visits, and $11 \%$ of medical admissions. Boys attend more frequently than girls, but only in proportion to the greater prevalence of asthma among boys.'

There was a substantial excess of young children, even when those under 18 months of age were excluded, and a greater proportion of the younger children required admission. A similar pattern was found among children admitted to hospital with acute asthma in Leeds. ${ }^{10}$ Management may be more difficult in young children and they may also have more severe attacks. Young children in our study were more likely to need intravenous treatment. McKenzie" young children admitted to hospital were more seriously ill than older ones. Parental anxiety is also often greater, especially if the asthma is of recent onset.

The timing of visits to our department showed a variation with season similar to that found for asthma admissions in the south east of England by $\mathrm{Khot}^{12}$ but a different picture from that seen in general practice, ${ }^{13}$ where children under 4 years attend most frequently in March and those aged 5-14 years in July. We found no constant relation between the number of attendances and the number of admissions each month. Variations cannot be related to changes of junior staff as the registrars, who make all decisions about admission, change post in April and October. There was little variation in the number of visits from day to day and, in contrast to the pattern seen in a general accident and emergency department, ${ }^{8}$ there was no increase in visits at the weekend. Visits by children were most common during the afternoon and evening, as with adults in Southampton and the Bronx.$^{814}$ Visits at night were unusual, which is a little surprising as worsening of asthma at night is well recognised. ${ }^{15}$ A study of emergency calls to the emergency doctor service and accident and emergency departments in London, ${ }^{16}$ however, found that, although there was a general reduction in calls at night, calls for asthma diminished much less than those for abdominal pain, a condition with no known diurnal variation.

The pattern of referral shows that $78 \%$ of children came to hospital without direct intervention by their general practitioner or a deputy. Sixty nine per cent of those admitted were self referred, as were $60 \%$ of the Leeds children studied by Conway, ${ }^{10}$ suggesting that the trend of increasing self referral described by Anderson $^{6}$ is continuing. Referrals from the deputising service were very infrequent, accounting for only $6 \%$ of visits. The deputising service is used by $91 \%$ of Liverpool practices ${ }^{17}$ and has a policy of referring all asthmatic children to hospital. Calls to the service for $\stackrel{\overrightarrow{\vec{S}}}{\vec{P}}$ asthma in children must be relatively uncommon.

Most children had been wheezy for a short time 흠 before coming to hospital, a pattern similar to that $\frac{\bar{m}}{\bar{a}}$ found in the Leeds study ${ }^{10}$ and among adults. ${ }^{9}$ We $\stackrel{\varnothing}{\varnothing}$ found, as did Conway, ${ }^{10}$ that apparent upper respiratory tract infections were the most common $\rightarrow$

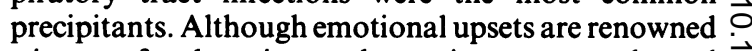
triggers of asthmatic attacks, excitement or upheaval $\overrightarrow{\vec{\omega}}$ were unusual, as was exposure to a recognisable $\stackrel{\omega}{\omega}$ antigen. Acknowledged omission of treatment was $\vec{x}$ unusual and, unlike among the adults of Southampton, no one came for a new inhaler. ${ }^{8}$

Details of treatment at home were not recorded with enough precision to separate regular treatment from $\bigcirc$ that used for the current attack, but some useful $\circ$ information can still be obtained. Eight per cent of $د$ children had received nothing, a slightly greater $\mathcal{D}$ proportion than in adults. ${ }^{8}$ Underdiagnosis and $\mathbb{D}$ undertreatment of asthma in children are known to be $\stackrel{\mathbb{D}}{\triangle}$ common, ${ }^{18}$ and may explain the difference. Most $\frac{3}{0}$ children had used a bronchodilator, including $11 \%$ who had received nebulised salbutamol. Prednisolone $\vec{\varphi}$ had been given to only 22 children $(2 \%)$ during the current attack, which is disappointing as several studies have shown the value of short courses. ${ }^{19}$ Twenty one per cent of children had been given antibiotics, for which a doctor's prescription would have been needed. Opportunities for effective early treatment seem likely to have been missed in some children who came to hospital.

Assessment of the severity of asthma and prediction of outcome on arrival at hospital is difficult. ${ }^{20}$ Nevertheless, we were worried to find, as did Reed in Southampton, ${ }^{8}$ how little information about the initial examination in hospital was recorded, and in particular how rarely PEF was recorded, even in older children, who could be expected to be able to perform the manouevre. Absence of distress does not exclude airway obstruction ${ }^{21}$ and objective measurement is vital. Peak flow measurements before and after treatment were particularly scarce. Studies in adults ${ }^{22}$ have shown that substantial subjective improvement may occur while considerable airway obstruction persists; apparent improvement does not mean that the child is of adequately treated and objective measurements must be made whenever possible if rational treatment is to be given.

In addition to possible shortfalls in treatment before attendance, treatment in the department also shows some inadequacies, mainly in the limited use of short courses of oral prednisolone in children sent home, despite the established value of such courses and the fact that $12 \%$ of children were taking inhaled corticosteroids. Management in the accident and emergency department in many ways reflects treatment at home, 
the only major difference being the universal use of nebulised bronchodilators in the hospital.

Admission rates show that half the children who attended were admitted. This a much greater admission rate than the $15-18 \%$ of asthmatic children attending emergency rooms in the United States, ${ }^{20}$ and slightly greater than in adults in England $(39 \%) .{ }^{8}$ Half of those who attended, however, were considered fit for discharge, though $16 \%$ of them returned later in the same attack, a much greater proportion than the $0.4 \%$ seen in Detroit. ${ }^{20}$ Differences in provision of emergency medical care in the United States and the United Kingdom are likely to contribute to this variation; but inappropriate initial treatment, in particular the limited use of prednisolone, may also be relevant.

Twenty one per cent of the children who were admitted needed intravenous treatment, a much smaller proportion than the $78 \%$ described by McKenzie in a more selected population." These children account for only $9 \%$ of all visits to the hospital for acute asthma. The remaining $91 \%$ were successfully managed with nebulised salbutamol or salbutamol plus oral prednisolone. Some of these children could perhaps have been managed at home.

Although most of the children attending were self referred, those referred by a doctor were more likely to be admitted. Anderson ${ }^{6}$ found that doctor referred children were usually iller on arrival in hospital than those who were self referred. Admitted children had more severe attacks and a shorter duration of symptoms than those discharged. In some fatal cases of asthma the interval between the onset of symptoms and death has been very short ${ }^{23}$ and caution is clearly necessary.

In conclusion, a study of accident and emergency department visits by a largely unselected population of urban children has shown acute asthma to be a common reason for attendance. We found shortcomings in treatment at home and in assessment and treatment in the department. Only half the children who attended required admission and only $9 \%$ intravenous treatment. In theory, many of the children who attended could have been managed at home, but $78 \%$ had come to the hospital without the intervention of their general practitioner or a deputy, a trend noted in other studies. Better understanding of the reasons why parents take their children to hospital is needed if optimal care is to be provided. In the meantime, large numbers of asthmatic children are likely to continue to attend accident and emergency departments. Appropriate training in the assessment and management of acute asthma should be arranged in all departments that care for children.

\section{References}

1 Lee DA, Winslow NR, Speight ANP. Prevalence and spectrum of asthma in childhood. Br Med J 1983;286: 1256-8.

2 Anderson HR, Bailey PA, Cooper JS, Palmer JC, West S. Medical care of asthma and wheezing illness: a community survey. J Epidem Commun Health 1983;37: 180-6.

3 Anon. Asthma - a challenge for general practice. J R Coll GP 1981;31:323-4.

4 Gregg I. Role of the family doctor in management. In: Clark TJH, Godfrey S, eds. Asthma. London: Chapman and Hall, 1983:496-501.

5 Mitchell EA. International trends in hospital admission rates for asthma. Arch Dis Child 1985;60:376-8.

6 Anderson HR, Bailey PA, West S. Trends in the hospital care for acute childhood asthma. $\mathrm{Br} \mathrm{Med} J$ 1980;281: $1191-4$

7 Anderson HR. Is the prevalence of asthma changing? Arch Dis Child 1989;64:172-5.

8 Reed S, Diggle S, Cushley MJ, Sleet RA, Tattersfield AE. Assessment and management of asthma in an accident and emergency department. Thorax 1985;40:897-902.

9 O'Halloran SM, Heaf DP. Recurrent Accident and Emergency Department attendance for acute asthma in children. Thorax 1989;44:620-6.

10 Conway SP, Littlewood JM. Admission to hospital with asthma. Arch Dis Child 1985;60:636-9.

11 McKenzie SA, Edmunds AT, Godfrey S. Status asthmaticus in children: a one year study. Arch Dis Child 1979;54:581-6.

12 Khot A, Evans N, Lenney W. Seasonal trends in childhood asthma in South East England. $\mathrm{Br} \mathrm{Med} J$ 1983;287:1257-8.

13 Ayres JG. Trends in asthma and hay fever in general practice in the United Kingdom. Thorax 1986;41: $111-6$.

14 Karetzky MS. Asthma in the South Bronx: clinical and epidemiological characteristics. J Allergy Clin Immunol 1977;60:383-90.

15 Turner-Warwick M. On observing patterns of airflow obstruction in chronic asthma. Br J Dis Chest 1977; 71:73-86.

16 Horn CR, Clark TJH, Cochrane GM. Is there a circadian variation in asthma morbidity? Br J Dis Chest 1987; 81:248-51.

17 O'Halloran SM, Heaf DP. Availability of nebuliser treatment for childhood asthma in general practice. Paed Rev Comm 1989;3:155-60.

18 Speight ANP, Lee DA, Hey EN. Underdiagnosis and undertreatment of asthma in childhood. $\mathrm{Br} \mathrm{Med} \mathrm{J}$ 1983;286:1253-6.

19 Deshpande A, McKenzie SA. Short courses of steroids in home treatment of children with acute asthma. $\mathrm{Br} \mathrm{Med}$ $J$ 1986;293:169-71.

20 Ownby DR, Abarzua J, Anderson JA. Attempting to predict hospital admission in acute asthma. Am J Dis Child 1984;138:1062-6.

21 Rubinfield AR, Pain MCF. Perception of asthma. Lancet 1976;i:882-4.

22 McFadden ER Jr, Kiser R, DeGroot WJ. Acute bronchial asthma: relations between clinical and physiological manifestations. $N$ Engl J Med 1973;288:221-5.

23 Carswell F. Thirty deaths from asthma. Arch Dis Child 1985;60:25-8. 